\title{
Inferior Rectal Artery
}

National Cancer Institute

\section{Source}

National Cancer Institute. Inferior Rectal Artery. NCI Thesaurus. Code C52938.

An artery arising from the internal pudendal artery that supplies the lower portion of the rectum and anastomoses with the superior and middle hemorrhoidal arteries. 